\title{
Experiment to save lives
}

\author{
Geohazards can be too dangerous to study directly but too deadly to ignore. For these types of events, data from \\ physical experiments can plug gaps in both hazard models and understanding.
}

T he devastation wreaked by pyroclastic density currents - hot mixtures of volcanic material and gas that can flow at hundreds of kilometres per hour - is undeniable. Directly responsible for more than one quarter of volcanic fatalities worldwide (Brown, S. K. et al. J. Appl. Volcanol. 6, 15; 2017), these currents are the deadliest volcanic phenomenon. The 1902 eruption of Mount Pelée is reported to have killed all but 3 of St. Pierre's 28,000-strong population. Most of these deaths were attributed to the complete destruction caused by pyroclastic density currents. The need to understand these incredibly fast flows is therefore driven by civil protection as much as scientific curiosity. In this Issue, Lube and colleagues present physical experiments, videoed through heat-resistant glass (https://go.nature.com/2Usv68B), that demonstrate that the speed of travel is made possible by the generation of a layer of air lubrication at the base of the flow.

Pyroclastic density currents are generated by the collapse of an eruption column or lava dome. With groundspeeds typically around 100 kilometres per hour and temperatures as high as $1,000^{\circ} \mathrm{C}$, they hurtle many kilometres from their source. The currents behave like a fluid, so topographic highs may offer little protection. This was sadly demonstrated during the 1991 Mount Unzen eruption, when a pyroclastic density current killed three pioneering volcanologists and the journalists that accompanied them despite their location on a ridge. Eye-witness accounts from the infamous 1883 Krakatoa eruption are evidence that even water is no defence, with burn fatalities reported far across the straits on the southern coast of Sumatra. These testimonials, as well as experiments (Freundt, A. Bull. Volcanol. 65, 144-164; 2003), show that when density currents encounter a water body, they can travel over its surface. Pyroclastic density currents can charge across many different terrains, indiscriminate in their destruction.

Today, hazard maps are produced using numerical models to quantify the risks to which areas around active

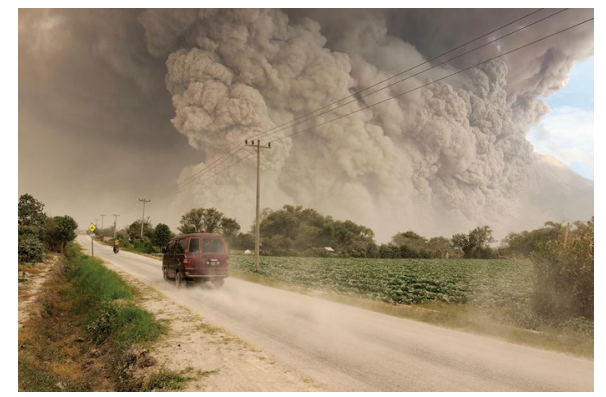

and speed that accompany pyroclastic density currents mean that there is no instrument that can be deployed and survive to release its data. Into this knowledge gap step the experimentalists. Experiments under idealized conditions make it possible to see inside the flow and to visualize and quantify internal processes that were previously only inferred.

Unfortunately, the costs of such experiments render them relatively rare in the Earth sciences. Not satisfied with a simple bench-top exploration, Lube and colleagues dumped 1.3 tonnes of hot volcanic material down a $12 \mathrm{~m}$ flume to simulate a volcanic pyroclastic density current. Although this experiment is large by laboratory standards, it is not a direct replica of the natural process. The volcanic particles in the experiment were hot, but only $130{ }^{\circ} \mathrm{C}$ compared with the 1,000 ${ }^{\circ} \mathrm{C}$ in natural flows. However, when the experiments were combined with numerical multiphase modelling, they revealed the internal mechanism that forms a cushion of air at the flow's base. This air cushion allows the density current to indiscriminately travel over land and water, much like a hovercraft, and is the key to the terrifying, almost frictionless mobility and speed of these currents.

Hazard assessment relies on models to quantify and evaluate risk. Effective implementation of this assessment depends on the trust people place in the results of the models. Therefore, one way to optimize their accuracy is through experiments. Physical experiments offer valuable data and mechanistic insight but they are inevitably scaled down. Therefore, the direct transfer of experimental insight into the real world is not a trivial task. The combination of numerical models and laboratory experiments should be encouraged, not just when life and livelihood are at stake, but when greater scientific insight is the likely reward.

Published online: 30 April 2019

https://doi.org/10.1038/s41561-019-0365-z 